\title{
META-ÉTICA COMO CONFIRMAÇÃO: A ANATOMIA MORAL DE
} HUME

\author{
Leonardo de Mello Ribeiro \\ Universidade Federal de Minas Gerais
}

\begin{abstract}
In The Sources of Normativity Korsgaard argues that Hume's moral project is to be interpreted as both naturalistic and normative. Our reconstruction of this interpretation claims that Korsgaard ascribes to Hume an argument analogous to the "regress argument", which has as a consequence the view that, on Hume's metaethics, human nature has unconditional (and intrinsic) value and, as such, is a source of practical normativity. If this is correct, Hume should be interpreted as a reductionist naturalist about moral value, trying to reduce evaluative statements to descriptive ones (about human nature). We shall offer reasons to resist this interpretation, denying that such a "regress argument" applies to Hume and defending the view that Hume's metaethics plays an explanatory role, but not justificatory, of our moral practices.
\end{abstract}

Keywords: Hume, Korsgaard, metaethics, ethics.

Resumo: Em The Sources of Normativity, Korsgaard defende que o projeto moral de Hume deve ser interpretado como naturalista e normativo. Nossa reconstrução desta interpretação propõe que Korsgaard atribui a Hume um argumento análogo ao "argumento do regresso", que teria como consequência a tese de que, na meta-ética Humeana, a natureza humana possui valor incondicional (e intrínseco) e é a fonte de normatividade prática. Se isto estiver correto, Hume deveria ser interpretado como um naturalista redutivista sobre valor moral, reduzindo enunciados valorativos a descritivos (sobre a natureza humana). Apresentaremos razões para resistir a esta interpretação, negando que tal "argumento do regresso" se aplique a Hume e defendendo que a sua meta-ética cumpre um papel explicativo, mas não justificatório, de nossas práticas morais.

Palavras-chave: Hume, Korsgaard, meta-ética, ética. 


\section{Introdução}

Hume termina o livro III do Tratado e a segunda Investigação com conclusões similares sobre o seu projeto moral ${ }^{1}$. Ele afirma em ambos que sua teoria diz respeito à "filosofia abstrata" ou "metafísica da moral”, e não propriamente à filosofia moral prática. No Tratado (e em outras obras) Hume traça esta distinção através de uma comparação entre o trabalho de um anatomista e o de um pintor ${ }^{2}$. Segundo Hume, o equivalente do anatomista, em assuntos morais, é aquele que investiga abstratamente os fundamentos da moral, enquanto que o do pintor é aquele que se propõe a enunciar os deveres ou requerimentos morais e a convencer a sua audiência da validade dos mesmos. Hume é um autoproclamado anatomista da moral.

Mas, ao mesmo tempo em que faz esta distinção, Hume afirma que a sua teoria abstrata ou metafísica pode ser de utilidade para a filosofia moral prática. Ele diz no Tratado:

$\mathrm{O}$ anatomista nunca deve emular o pintor; nem deve, em suas cuidadosas dissecções e em suas descrições das partes mais diminutas do corpo humano, querer dar às suas figuras atitudes ou expressões graciosas e atraentes. Existe mesmo algo repulsivo, ou ao menos desprezível, na visão que nos fornece das coisas; é necessário situar os objetos mais à distância, torná-los menos visíveis, para que se tornem mais atraentes para o olho ou a imaginação. $O$ anatomista, entretanto, é admiravelmente bem qualificado para aconselhar o pintor; chega a ser impraticável atingir a perfeição nesta última arte sem o auxílio da primeira. Temos que ter um conhecimento exato das partes, de sua posição e conexão, para podermos desenhar com elegância e correção. Assim, as especulações mais abstratas acerca da natureza humana, por mais frias e sem graça que sejam, fazem-se um instrumento da moral prática; e podem tornar esta última ciência mais correta

\footnotetext{
${ }^{1}$ As principais obras de Hume serão referidas de acordo com as seguintes abreviações: $A$ Treatise of Human Nature: THN; Enquiry concerning Human Understanding: EHU; Enquiry concerning the Principles of Morals: EPM.

${ }^{2}$ A distinção, nestes termos, aparece também em EHU e em carta de Hume a Hutcheson. Porém, a ideia de uma anatomia da moral não é original em Hume. Ela já está presente em SHAFTESBURY, 1727, II.1.ii, p. 83-4.
} 
em seus preceitos e mais persuasiva em suas exortações. (THN, III.iii.6, p. 620-1).

Portanto, uma questão de relevância para a interpretação do projeto moral Humeano parece ser que relações Hume supõe que existem entre sua teoria abstrata ou metafísica e nossas convicções e práticas morais, entre uma "anatomia da moral" e uma "pintura da moral". Como sabemos, a teoria abstrata ou metafísica de Hume é, em larga medida, uma teoria meta-ética sobre a natureza dos juízos morais, sua origem e base psicológica. Neste sentido, a teoria é eminentemente uma teoria explicativa de juízos morais e do comportamento moral. Por outro lado, Hume parece entender por 'filosofia prática moral' o conjunto de prescrições que regem a nossa conduta em interrelações pessoais. Se estas observações estiverem corretas, cabe então perguntar: que tipo de verdades explicativas meta-éticas (de segunda-ordem) poderiam ser relevantes para a formulação e defesa de juízos éticos de primeira-ordem?

Esta é, obviamente, uma questão deveras ampla que não poderemos investigar aqui em sua totalidade. Mas importa-nos avaliar um aspecto particular desta questão, tal como ela é apresentada especificamente na conclusão do Tratado. Vejamos este aspecto particular.

Hume, no Tratado, diz que o "senso moral" - que é a perspectiva através da qual expressamos juízos morais e cujo funcionamento é uma das descobertas de sua investigação abstrata ou metafísica - é capaz de refletir sobre si próprio, seus princípios e origem. Segundo Hume, o resultado desta reflexão é uma autoaprovação do senso moral, que "reforça" os sentimentos morais. Hume diz:

Um ligeiro conhecimento dos assuntos humanos é suficiente para se perceber que o senso da moralidade é um princípio inerente à alma, e um dos elementos mais poderosos de sua composição. Mas esse senso deve certamente ganhar mais força quando, ao refletir sobre si próprio, aprova os princípios de que deriva, sem encontrar em seu nascimento e origem nada que não seja grande e bom. (...) [N]ão é apenas a virtude que deve ser aprovada, mas também o senso da virtude; e não apenas esse senso, mas também os princípios de que ele deriva. De modo que, de todos os lados, não se apresenta nada que não seja louvável e bom. (THN, III.iii.6, p. 619). 
Com base nesta passagem, podemos conjecturar que Hume parece propor uma espécie de teste pelo qual o trabalho do anatomista pode ser avaliado à luz da atividade do pintor. Como seres capazes de reflexão, podemos investigar o funcionamento de nossas próprias faculdades mentais. Tendo assim formulado uma teoria acerca da origem, natureza e psicologia dos juízos morais - que compõe a teoria abstrata ou metafísica Humeana dos princípios da moral ${ }^{3}$ - a própria perspectiva da prática moral pode agora refletir sobre estes mesmos princípios (abstratos ou metafísicos) e, ainda que não possa interferir em sua verdade ou falsidade, pode "desaprová-los" se a sua verdade estiver em conflito com a própria prática da moralidade ${ }^{4}$. Mas, por outro lado, os princípios abstratos ou metafísicos da moral poderiam reforçar a prática moral se, ao refletir sobre estes, o senso moral os aprovasse por eles, de alguma forma, se harmonizarem com a própria prática da moralidade 5 .

Podemos chamar esse teste, ainda que imprecisamente, de um teste da "validade moral" da teoria Humeana abstrata ou metafísica dos fundamentos da moralidade. Tal teste consistiria em uma espécie de avaliação dos princípios explicativos da moralidade. Se as verdades da teoria abstrata ou metafísica revelassem uma convergência entre esta e a prática da moral - isto é, entre a natureza dos nossos juízos morais e a nossa perspectiva de juízes morais - então a teoria abstrata ou metafísica teria validade moral - isto é, ela poderia ser revelada em exortações morais (pelo "pintor") a fim de produzir convencimento moral. Neste caso, a teoria abstrata ou metafísica forneceria um tipo de suporte à prática moral.

\footnotetext{
${ }^{3}$ Teoria que aparece sobretudo em THN (II.iii.3; III.i.1; III.i.2) e EPM (Seções I e IX; Appendix I).

${ }^{4}$ Hume diz algo similar a isto em EPM: "E ainda que a verdade filosófica de qualquer proposição não dependa absolutamente de sua tendência a promover os interesses da sociedade, seria uma tarefa muito ingrata apresentar uma teoria que, embora verdadeira, tivesse de ser reconhecida como algo que conduz a práticas nocivas e perigosas. Por que vasculhar aqueles recantos da natureza que espalham transtornos por todo seu redor? Por que exumar a pestilência da cova em que está sepultada? A engenhosidade de tais investigações pode produzir admiração, mas os sistemas decorrentes serão detestados e a humanidade concordará, se não puder refutá-los, ao menos lançá-los ao eterno silêncio e olvido. Verdades que são perniciosas à sociedade, se as houver, cederão lugar a erros que são saudáveis e vantajosos." (EPM, IX.ii, p. 279).

${ }^{5}$ Hume diz: "Se fosse apropriado, em um assunto como este, subornar o leitor, e empregar algo mais que argumentos sólidos para conseguir seu assentimento, isso não seria difícil, pois temos aqui à nossa disposição uma grande abundância de tópicos para cativar os afetos. Todos os amantes da virtude (e, em teoria, todos nós 0 somos, embora possamos nos degenerar na prática) certamente devem ficar satisfeitos em ver que as distinções morais são derivadas de uma fonte tão nobre, que nos dá uma noção correta tanto da generosidade quanto da capacidade de nossa natureza." (THN, III.iii.4, p. 619)
} 
Hume é claramente um entusiasta com relação aos resultados de seu trabalho como anatomista moral. E este entusiasmo parece ter, ao menos em parte, relação com o fato de a sua teoria abstrata ou metafísica fazer referência à natureza humana como sua base última, uma vez que a anatomia moral de Hume mostra que a origem da moralidade está nesta própria natureza humana, em sua forma psicológica ${ }^{6}$.

Mas por que a origem da moralidade fazer referência à natureza humana consistiria em uma vantagem da teoria abstrata ou metafísica de Hume? Aqui retornamos, em parte, a uma pergunta anterior: como uma explicação (meta-ética) psicológica de nosso comportamento moral poderia reforçar nossos juízos morais de primeira-ordem sobre traços de caráter e ações? Veremos que Hume parece pensar que o fato de a natureza humana estar na base da moralidade produz aprovação de nosso senso moral. Isto porque, sendo natural a nós, seres humanos, o mecanismo que produz distinções e avaliações morais, Hume poderia dizer, por exemplo: que a explicação do fenômeno da moralidade não precisa ser metafisicamente inflacionada; que o caráter prático da moralidade se harmoniza àquela ideia; que o discurso moral não é meramente ficcional, resultado de processos manipuladores para a preservação da ordem social; que o fenômeno da moralidade não é inteiramente artificial e não serve unicamente para satisfazer e preservar nossas naturezas egoístas. Todos estes temas são caros a Hume. E ele parece crer que tais conclusões significativas sobre a natureza do fenômeno da moralidade poderiam ser extraídas do fato de a origem do mesmo residir na própria natureza humana. Mas antes de considerarmos esta proposta mais detalhadamente, cabe avaliar uma outra possível intepretação para aquela relação.

Uma maneira de interpretar a relação em jogo seria sugerir que enunciados e juízos morais são redutíveis aos processos psicológicos (ou estados mentais) que compõem o senso moral. Neste sentido, a moralidade

\footnotetext{
${ }^{6}$ Citando uma passagem, em THN (III.iii.1, p. 575-8), Hume diz, sobre o mecanismo psicológico da simpatia, que ele pensava ser uma grande descoberta sua sobre a base do comportamento moral: "As mentes de todos os homens são similares em seus sentimentos e operações (...) Assim, parece que a simpatia é um princípio muito forte na natureza humana, que possui grande influência sobre nosso gosto do belo e que produz nosso sentimento de moralidade em todas as virtudes artificiais. Disto podemos presumir que ela também dá origem a muitas outras virtudes; e que certas qualidades recebem nossa aprovação em função de sua tendência para 0 bem da humanidade. Esta suposição se torna necessariamente uma certeza quando descobrimos que a maior parte das qualidades que naturalmente aprovamos têm, de fato, aquela tendência: tornam os homens bons membros da sociedade (...)".
} 
seria reforçada por uma anatomia da moral que revelasse um processo duplo de explicação e justificação da prática da moralidade; e cujo fundamento, no modelo de Hume, seria a redução do conteúdo da moralidade a manifestações (específicas) da natureza humana. Propor isto seria propor que a reflexão sobre o senso moral conferiria normatividade ou autoridade aos princípios abstratos ou metafísicos deste mesmo senso moral, na medida em que estes princípios revelariam que a natureza humana é a condição última e medida de valor de todas as coisas. Neste sentido, agir segundo os princípios abstratos ou metafísicos do senso moral (que fazem referência a manifestações específicas da natureza humana) seria um "dever", isto é, tais princípios seriam normativos para nós. Portanto, aprovar o senso moral, segundo esta linha interpretativa, seria conferir-lhe normatividade e reconhecer a sua autoridade, ao propor a redutibilidade do mesmo a manifestações específicas da natureza humana, reveladas pela teoria abstrata ou metafísica da moral de Hume.

Recentemente, Christine Korsgaard parece ter sugerido que interpretemos o projeto moral de Hume justamente naquele sentido duplo explicativo e justificatório - na esteira de um projeto redutivista de enunciados morais a enunciados descritivos sobre a natureza humana. Korsgaard diz:

Se a explicação verdadeira da nossa natureza moral fosse tal que nos levasse a rejeitar as suas exigências, então os filósofos práticos, como os guardiões $\mathrm{da}$ ordem social, deveriam garantir que a verdade não fosse descoberta. Mas se os filósofos práticos podem fazer com que as pessoas aceitem as exigências da moralidade simplesmente contando a elas a verdade sobre a natureza da moralidade, então as exigências da moralidade estão justificadas. Hume está afirmando que a sua teoria é normativa 7 .

Pode ser considerada uma virtude da interpretação de Korsgaard o fato de ela encontrar espaço para normatividade, para requerimentos morais, no projeto moral de Hume ${ }^{8}$. Porém, ainda que concedamos isto a Korsgaard,

\footnotetext{
${ }^{7}$ KORSGAARD, 1996a, p. 54.

${ }^{8}$ Ao contrário de autores como KEMP-SMITH, 1941, p. 201, e IRWIN, 2007, p. 662ss., que argumentam não haver espaço para normatividade ou requerimentos morais no projeto moral de Hume.
} 
podemos ter razões para rejeitar a interpretação sugerida por ela sobre como garantir normatividade no projeto moral de Hume. Neste artigo, nosso objetivo é tentar mostrar que temos efetivamente tais razões.

Ao contrário da interpretação de Korsgaard, proporemos que temos razões para crer que o projeto de Hume confere um caráter não-reducionista ao pensamento e discurso morais, que é incompatível com o tipo de interpretação proposta por Korsgaard. Ao defender esta tese interpretativa, tentaremos também tornar mais clara qual o veredicto que a reflexão do senso moral sobre si mesmo pode gerar, segundo Hume. Este, tal como defenderemos, aponta para uma relação de confirmação e não de justificação (do conteúdo) da prática moral. A teoria abstrata ou metafísica (meta-ética) de Hume é uma teoria explicativa sobre a origem de nossos juízos morais e nosso comportamento moral; não é uma teoria justificatória da moralidade muito menos uma teoria redutivista naturalista. A lição de Hume é que a moralidade só pode ser justificada (moralmente) pela perspectiva interna à própria moralidade e, neste sentido, ela é, portanto, irredutível a qualquer outra perspectiva 9 .

Ao interpretar o projeto de Hume nestes termos, teremos também a oportunidade de apontar aquilo que parece levar Korsgaard a (erroneamente) propor que, para que haja normatividade ou requerimentos morais na teoria Humeana, a única solução é uma redução de enunciados morais a enunciados (descritivos) sobre a natureza humana. Veremos como este pensamento parece envolver uma concepção estreita sobre o status de requerimentos morais. E, à luz da comparação da teoria moral de Hume com as teorias de Hutcheson e Butler, apontaremos uma direção, ainda que de forma meramente esquemática, sobre como a tese de Hume pode dar sentido a requerimentos morais, baseando-os na natureza humana, mas não reduzindo-os a esta.

Assim, como deve estar claro, o objetivo deste artigo é eminentemente negativo. O objetivo primário é mostrar que a teoria abstrata ou metafísica Humeana dos princípios da moral não é uma teoria justificatória do conteúdo da moralidade, mas apenas uma teoria explicativa do comportamento moral.

\footnotetext{
${ }^{9}$ Este parece ser um dos pontos centrais de Hume em seu ensaio "The Sceptic".
} 


\section{2 - Um argumento do regresso Humeano?}

Christine Korsgaard sugere, em seu The Sources of Normativity, que uma maneira de compreender a relação entre a teoria abstrata ou metafísica e a teoria prática da moralidade, no texto de Hume, é mostrar que a teoria moral Humena é naturalista e normativa. Segundo Korsgaard, isto significa dizer que uma teoria metafísica naturalista dos princípios da moralidade poderia não apenas explicar o comportamento moral como também justificálo. Como veremos, Korsgaard sugere que a única maneira de se fazer isto seria, em última instância, reduzindo enunciados morais a enunciados (descritivos) sobre a natureza humana.

Acerca da atitude de Hume com relação à lacuna entre o anatomista e o pintor, Korsgaard diz que

[e]mbora ele [i.e., o anatomista] não seja, em tese, alguém fazendo filosofia prática, Hume não pode evitar observar que a sua explicação da origem das ideias morais efetivamente torna a virtude atrativa ${ }^{10}$.

E, de modo mais explícito, Korsgaard explica como a anatomia moral de Hume pode servir de "bandeira" para a causa da virtude moral:

[A teoria de Hume] mostra que a natureza humana, incluindo a moralidade, é intrinsicamente normativa, em uma versão negativa (...): não há qualquer desafio inteligível que possa ser levantado às suas exigências. (...) Fora da natureza humana não há qualquer ponto de vista normativo a partir do qual a moralidade possa ser questionada. Mas a moralidade pode superar o desafio interno que é levantado pelo ponto de vista do interesse pessoal, e ela também aprova a si mesma. (...) Não temos, portanto, qualquer razão para rejeitar a nossa natureza, e podemos admiti-la como uma lei para nós. A natureza humana, incluindo a moralidade, é portanto normativa e tem autoridade para nós ${ }^{11}$.

${ }^{10}$ KORSGAARD, 1996a, p. 53.

11 lbid., p. 65-6. 
Resumidamente, a ideia de Korsgaard pode ser descrita do seguinte modo. O projeto de Hume inicia com a rejeição do realismo moral (com base em uma série de argumentos que nos são familiares, mas que não serão objetos de nossa investigação aqui) ${ }^{12}$. Enunciados morais não representam uma realidade ou entidades morais porque não há genuínas propriedades morais. Hume propõe-se, então, a fundar a moralidade em algo interno à natureza humana: sentimentos e disposições naturais dos seres humanos. Juízos e discurso morais são projeções sobre questões de fato destes sentimentos e disposições ${ }^{13}$.

Mas, além disso, segundo Korsgaard, a história Humeana sobre o fundamento da moralidade em sentimentos e disposições naturais humanas não é meramente uma história explicativa sobre o nosso comportamento moral e sobre a natureza e origem dos juízos morais. Ela é também uma história que justifica enunciados morais de primeira-ordem e nosso comportamento moral. É isto o que Korsgaard parece entender do projeto Humeano ao dizer que a explicação da origem das ideias morais torna a virtude não apenas atrativa, mas também normativa.

Mas como exatamente isto pode ser feito no contexto da filosofia moral de Hume? Segundo Korsgaard, tendo descoberto que juízos de valor estão baseados em (ou são dependentes de) sentimentos e disposições naturais humanos, há dois tipos possíveis de perspectivas valorativas a partir das quais podemos avaliar traços de caráter e ações. Estas são a perspectiva do interesse pessoal e a perspectiva da própria moralidade. Korsgaard defende que a moralidade, para Hume, passa no teste de ambas as perspectivas. Por um lado, inspirado pelos argumentos de Shaftesbury, Hutcheson e Butler, Hume tenta mostrar que a moralidade não é incompatível com o interesse pessoal ${ }^{14}$. E, por outro lado, a moralidade aprova a si mesma, quando o senso moral reflete sobre si mesmo.

\footnotetext{
12 Estes argumentos aparecem sobretudo em THN (II.iii.3; III.i.1). Para uma apresentação e discussão instrutiva dos mesmos, ver MACKIE, 1980, cap. III e IV.

13 KORSGAARD (1996a, p. 91) resume o projeto de Hume: "a moralidade é baseada na natureza humana. Obrigações e valores são projeções de nossos próprios sentimentos e disposições. Dizer que estes sentimentos e disposições estão justificados não é dizer que eles descobrem a verdade, mas é simplesmente dizer que eles são bons." Korsgaard atribui o mesmo projeto a Mill e Williams, que ela chama de 'reflective endorsement'. (Ver KORSGAARD, 1996a, lecture 2.)

${ }^{14}$ Este é um tema comum a todos estes autores, que se propunham a refutar os modelos psicológicos egoístas de autores como Hobbes e Mandeville. Ver SHAFTESBURY, 1727, II; HUTCHESON, 1729, II.i/ii/iii; BUTLER, 1983, IV, V.
} 
Assim, segundo Korsgaard, isto justificaria a moralidade em um sentido negativo. Não há qualquer razão para não sermos morais, em que isto agora significa 'não há qualquer razão para rejeitarmos a nossa natureza'. A moralidade aprova a si mesma e a moralidade passa no desafio do interesse pessoal. Não ser moral leva-nos a não apenas prescindir das gratificações (ou benefícios) naturais da própria vida virtuosa moral, mas também a sofrer punições específicas da nossa própria natureza ${ }^{15}$.

É neste sentido que Korsgaard sugere que a teoria de Hume é normativa e gera requerimentos morais. Na medida em que a teoria identifica a origem da moralidade na natureza humana, na forma de sentimentos específicos naturais (que estão na base daquilo que identificamos no fenômeno da moralidade), ela deve, ao refletir sobre si mesma, reconhecer que as manifestações últimas daquela natureza têm autoridade sobre nós. A ideia de Korsgaard parece ser que, se não houvesse uma aprovação do senso moral (isto é, dos princípios explicativos, abstratos ou metafísicos, em sua base) que lhe conferisse um papel normativo - estabelecendo que o senso moral é fonte de dever e lei, pois tem autoridade sobre nós por possuir valor intrínseco e ser incondicional - não poderia haver justificação de requerimentos morais ${ }^{16}$.

Feitas estas considerações, estamos agora em condições de formular mais precisamente o argumento que Korsgaard parece atribuir a Hume. O argumento que ela identifica em Hume, que mostra como normatividade pode ter origem na natureza humana, parece ser, em termos gerais, o seguinte. Na medida em que juízos morais estão baseados em certas reações nossas (sentimentos e disposições naturais específicos) que conferem valor a traços de caráter e ações, deve haver algo que confere valor a estas mesmas reações, uma vez que estas podem ser questionadas a partir de nossa

\footnotetext{
${ }^{15}$ Cf. KORSGAARD, 1996a, p. 51-66. A ideia de Korsgaard é propor que, para Hume, sofremos sanções de nossa própria natureza por sermos imorais; em cujo caso o projeto de Hume seria similar ao de Hobbes, com a diferença de que, em Hobbes, as sanções são oriundas do Soberano. Ver KORSGAARD, 1996a, p. 66, nota 37.

16 Obviamente, nem toda manifestação da natureza humana será representativa desta, no sentido relevante para a identificação do fenômeno da moralidade. Apenas algumas manifestações serão representativas de uma "genuína natureza humana". [Hume diz que "distinções morais dependem inteiramente de certos sentimentos peculiares de prazer e dor." (THN, III.iii.1, p. 574, grifo nosso.)] Isto significa, em parte, que a própria noção de natureza humana aqui em uso já é, de alguma forma, moralizada ou normativa. Podemos, assim, compreender que é neste sentido que Korsgaard sugere que é um aperfeiçoamento da nossa natureza que Hume tem em mente: a correção de disposições morais, de que Hume fala, significaria que certas disposições são normativas para nós.
} 
perspectiva reflexiva - do contrário, não estaríamos ultimamente justificados em conferir valor aos objetos de nossos próprios juízos morais. Em algum momento neste processo justificatório (regressivo às condições últimas de justificação) deve haver algo que seja a fonte fundacional - uma "condição incondicional" - do valor de todas as outras coisas e que, assim, também é a fonte do valor daquelas mesmas reações; quer dizer, algo para além do que não faria sentido perguntar por uma justificação adicional. Segundo Korsgaard, no modelo de Hume, tal condição incondicional é a natureza humana, na forma de sentimentos naturais (que figuram na base do fenômeno da moralidade).

Se esta for uma interpretação adequada da proposta de Korsgaard, ela parece, então, atribuir a Hume uma versão análoga do argumento do regresso, que ela identifica em Kant. Com uma diferença, porém, significativa: enquanto que a conclusão do argumento do regresso Kantiano é a de que a racionalidade é a medida de valor de todas as coisas e que esta, portanto, tem valor em si mesma, a conclusão do argumento do regresso Humeano é a de que a natureza humana é a medida de valor de todas as coisas e que esta, portanto, tem valor em si mesma. Em uma breve digressão que nos será útil, vejamos, primeiramente, o argumento do regresso Kantiano, tal como entendido por Korsgaard, e, posteriormente, como este parece ser aplicado por ela a Hume.

A atribuição do argumento do regresso a Kant faz parte de uma tendência recente entre comentadores - que tem em Korsgaard um de seus mais vigorosos representantes - que afirmam que Kant aplica uma modalidade do clássico argumento do regresso em sua apresentação da fórmula da humanidade do imperativo categórico. Em termos gerais, o argumento consiste em um processo de justificação que termine com uma proposição que não é possível mais questionar ${ }^{17}$.

No contexto do projeto moral Kantiano, em termos gerais e resumidos, o ponto de partida é perguntar o que justifica nossa crença de que o objeto de nossas escolhas racionais é bom. Tendo rejeitado que tal resposta possa ser dada investigando-se as relações causais entre objetos no mundo ou

$17 \mathrm{O}$ argumento do regresso figura tradicionalmente nas discussões de epistemologia acerca da justificação de crenças. Em linhas gerais, segundo o argumento, qualquer processo de justificação de crenças precisaria ele mesmo ser composto de crenças justificadas. Os detalhes desta história não nos interessam aqui. Interessa-nos notar, por outro lado, que o mesmo tipo de argumento pode ser aplicado a discussões morais. Para uma formulação em termos morais, ver SINNOTT-ARMSTRONG, 1996. 
no domínio das aparências, ${ }^{18}$ Kant considera que nossas crenças acerca daquilo que é bom devem ser justificadas de outra maneira. $\mathrm{Na}$ medida em que Kant rejeita que inclinações, ou qualquer outro elemento empírico possa fornecer tal justificativa - porque nada de empírico pode ter valor intrínseco, uma vez que qualquer elemento empírico pode ter a sua bondade questionada, segundo Kant, por ser, inter alia, algo contingente - ele conclui que a racionalidade fornece tal justificativa, de maneira fundacional. Neste sentido, o projeto de Kant é trivialmente racionalista.

Korsgaard diz que,

em um regresso às condições, descobrimos que a condição incondicional do valor de qualquer coisa é a natureza racional, ou o poder de escolha racional. Para exercer este papel, porém, a natureza racional deve ela própria ser algo de valor incondicional - um fim em si mesma ${ }^{19}$.

Isto porque:

Kant percebeu que nós consideramos objetos importantes porque eles são importantes para nós - e concluiu que devemos, portanto, considerar nós mesmos importantes. Dessa forma, o valor da humanidade está ele próprio implícito em toda escolha humana. Se o ceticismo normativo deve ser evitado - se há tais coisas como razões para agir então a humanidade como a fonte de todas razões e valores deve ser valorizada por si mesma ${ }^{20}$.

Mais precisamente,

O argumento é transcendental em um sentido trivial: nós consideramos alguns de nossos fins bons [ou de valor positivo], embora eles sejam obviamente condicionais; deve existir uma condição de sua bondade [de seu valor positivo];

\footnotetext{
18 Algo que Kant supostamente estabelece na Crítica da Razão Pura. Como diz Timmermann, "0 idealismo transcendental confina o conhecimento humano ao domínio das aparências governadas pelas leis da causalidade natural e desprovido de valor." (TIMMERMANN, 2006, p. 69).

19 KORSGAARD, 1996b, p. 123.

20 KORSGAARD, 1996a, p. 122. Ver também KORSGAARD (1996c) para uma discussão geral desta proposta interpretativa do projeto moral Kantiano, em oposição a uma proposta realista.
} 
consideramos que eles são bons sempre que são escolhidos com autonomia racional plena; portanto, autonomia racional plena é ela mesma a fonte do valor dos fins ${ }^{21}$.

Em termos (um pouco) mais formais, poderíamos tentar expressar o argumento de Korsgaard da seguinte forma:

K1. Os objetos de nossas escolhas racionais autônomas têm valor.

K2. (Tais) Objetos ou têm valor independentemente de nossas escolhas racionais autônomas (nós os escolhemos porque eles têm valor) ou têm valor porque nossas escolhas racionais autônomas lhes conferem valor (eles têm valor porque nós os escolhemos).

K3. Realismo moral é a tese segundo a qual os objetos (de nossas escolhas racionais autônomas) têm valor independentemente de nossas escolhas racionais autônomas.

K4. O realismo moral é falso.

K5. Os objetos de nossas escolhas racionais autônomas não têm valor independentemente de nossas escolhas racionais autônomas. [segue-se de K3 e $\mathrm{K} 4]$.

K6. Conferimos valor a (tais) objetos através das nossas escolhas racionais autônomas. [segue-se de $\mathrm{K} 2$, K3 e K4].

K7. Portanto, os objetos de nossas escolhas racionais autônomas têm valor simplesmente porque são objetos de nossas escolhas racionais autônomas. [segue-se de K2, K3, K4 e K6 (?)].

K8.Tudo o que tem valor ou é um objeto de uma escolha racional autônoma ou é a própria natureza racional autônoma (i.e., a capacidade de realizar escolhas racionais autônomas). [segue-se de K2, K3, K4 e K7].

K9. A natureza racional autônoma é a condição incondicional de possibilidade de valor de qualquer objeto.

K10. Para que qualquer coisa seja a condição incondicional do valor de qualquer objeto, esta própria coisa deve ter valor intrínseco.

K11. A natureza racional autônoma tem valor intrínseco. [segue-se de K9 e K10].

K12. Se a natureza racional autônoma tem valor intrínseco, então ela é a fonte de razões para nós e, portanto, normativa. [segue-se de uma análise conceitual de 'razões'] ${ }^{22}$.

${ }^{21}$ KORSGAARD, 1996d, p. 240-1. 
Não é nosso propósito aqui discutir a validade deste argumento e nem avaliar se ele é uma interpretação adequada dos escritos de $\mathrm{Kant}^{23}$. Importa-nos apenas apresentá-lo a fim de sermos capazes de formular uma variante do mesmo que parece ser atribuída a Hume por Korsgaard para, então, perguntar sobre se o mesmo se aplica a Hume.

$\mathrm{Na}$ medida em que Hume sugere em algumas passagens que enunciados morais significam não mais do que a presença de um sentimento de prazer ou dor, o simples reportar destas manifestações como fatos psicológicos naturais pareceria fornecer o conteúdo da moralidade e a sua justificação (ao fornecer o significado de termos e enunciados morais). Não seria possível ir além destas respostas subjetivas da natureza humana para fundar a moralidade. Para argumentar a favor disto, Korsgaard parece se apoiar em passagens como esta, em que se perguntando sobre uma ação indiscutivelmente viciosa, Hume diz:

Examinemo-la sob todos os pontos de vista, e vejamos se podemos encontrar o fato, ou existência real, que chamamos de vício. Como quer que a tomemos, encontraremos somente certas paixões, motivos, volições e pensamentos. Não há qualquer outro fato neste caso. $\mathrm{O}$ vício nos escapa por completo, enquanto consideramos o objeto. Não o encontraremos até dirigirmos nossa reflexão para nosso próprio íntimo, e darmos com um sentimento de desaprovação, que se forma em nós contra essa ação. (...) De modo que, quando declaramos que uma ação ou um caráter é vicioso, tudo que queremos dizer é que, dada a constituição de nossa natureza, experimentamos uma sensação ou sentimento de censura quando os contemplamos. (THN, III.i.1, p. 468-9) ${ }^{24}$.

Diante de passagens como esta, Korsgaard parece efetivamente ter, à primeira vista, razões para atribuir uma teoria normativa redutivista

\footnotetext{
${ }^{22}$ A formulação deste argumento, em termos similares, pode ser encontrada em RIDGE, 2005, do qual nos beneficiamos grandemente.

${ }^{23}$ Uma crítica a esta interpretação de Kant pode ser encontrada em TIMMERMANN, 2006.

${ }^{24}$ De maneira similar, em EPM, Hume diz: "A hipótese que adotamos (...) sustenta que a moralidade é determinada pelo sentimento. Ela define virtude como qualquer qualidade ou ação mental que dá ao espectador o sentimento agradável de aprovação; e vício o contrário." (EPM, Appendix I, p. 289)
} 
naturalista a Hume. O ponto fundamental é que, segundo Hume sugere na passagem em consideração, tais respostas da natureza humana seriam elas mesmas normativas por serem o que queremos dizer com o vocabulário moral, isto é, elas serviriam como critério daquilo que é certo ou errado.

Assim, tal como entendemos a sugestão de Korsgaard, ao propor que o modelo de Hume é normativo naqueles termos, ela parece supor que o argumento para tal é similar ao de Kant, a saber, o de derivar enunciados normativos de primeira-ordem de premissas meta-éticas ${ }^{25}$. Assim, o projeto meta-ético de Hume seria naturalista não apenas no sentido de explicar a origem da moralidade através da natureza humana. Ele seria um projeto meta-ético naturalista muito mais robusto: o de reduzir enunciados morais a enunciados sobre a natureza humana e, ao fazer isto, concluir que a fonte da moralidade, as manifestações últimas da natureza humana, deve ser ela mesma dotada de valor e, portanto, normativa.

Eis a nossa reconstrução do argumento do regresso que Korsgaard parece atribuir a Hume:

H1. Os objetos de nossos sentimentos naturais de aprovação têm valor $^{26}$.

H2. (Tais) Objetos ou têm valor independentemente de nossos sentimentos naturais de aprovação (nós os aprovamos porque têm valor em si) ou têm valor porque nossos sentimentos naturais de aprovação lhes conferem valor (eles têm valor porque nós naturalmente os aprovamos).

H3. Realismo moral é a tese segundo a qual objetos têm valor independentemente de nossos sentimentos naturais de aprovação.

H4. O realismo moral é falso.

H5. Os objetos de nossos sentimentos naturais de aprovação não têm valor independentemente de nossos sentimentos naturais de aprovação.

\footnotetext{
25 No caso de Kant, pode-se dizer que sua fundamentação da moral parte de premissas sobre a natureza da racionalidade e do agir racional para conclusões sobre o conteúdo da moral (ou das injunções morais). Neste sentido, o projeto de Kant pode ser considerado redutivista por reduzir 0 conteúdo da moralidade à (faculdade da) racionalidade (prática).

${ }^{26}$ Estritamente falando, sentimentos e paixões não possuem objetos, na teoria de Hume. Isto está na base da afirmação de Hume de que paixões são existências originais e não-representacionais. (THN, II.iii.3) Porém, por outro lado, é óbvio que Hume associa sentimentos e paixões a outras impressões e ideias (a teoria da dupla relação entre impressões e ideias é baseada nisto) que poderiam ser compreendidas, de alguma forma, como sendo os objetos de sentimentos e paixões - ou, ao menos, estados de coisas com que estão relacionados. Sendo assim, pressupomos que podemos omitir esta objeção.
} 
H6. Conferimos valor a (tais) objetos através de nossos sentimentos naturais de aprovação.

H7. Portanto, os objetos de nossos sentimentos naturais de aprovação têm valor simplesmente porque são objetos de nossos sentimentos naturais de aprovação.

H8. Tudo o que tem valor ou é um objeto de nossos sentimentos naturais de aprovação ou é a própria natureza humana [responsável pelos sentimentos naturais de aprovação].

H9. A natureza humana é a condição incondicional de possibilidade de valor de qualquer objeto.

H10. Para que qualquer coisa seja a condição incondicional do valor de qualquer objeto, esta própria coisa deve ter valor intrínseco.

H11. A natureza humana tem valor intrínseco.

H12. Se a natureza humana tem valor intrínseco, então ela é a fonte de razões para nós e, portanto, normativa.

Como alguém tocado pela tradição Kantiana, Korsgaard julga tal argumento inaceitável. Algumas de suas premissas são falsas, segundo ela. Afinal, tal argumento não atende à reivindicação básica de Kant da autonomia e do caráter necessário de juízos morais. Ele, no máximo, fornece uma história coerente sobre a heteronomia e a contingência da prática moral.

Não é nosso propósito aqui argumentar em que sentido um projeto supostamente heterônomo como o de Hume poderia responder a essa objeção Kantiana. O nosso propósito é mais modesto: é tentar mostrar que tal argumento não se aplica a Hume.

Se a interpretação de Korsgaard fizer sentido, então haveria uma convergência entre o conteúdo da moralidade e a teoria abstrata ou metafísica de Hume, na medida em que esta forneceria uma análise do conceito de moralidade. Desse modo, uma vez que a investigação de Hume revela os mecanismos naturais que levam às atitudes psicológicas de aprovação ou reprovação de determinados traços de caráter e determinadas ações, seriam estas mesmas atitudes psicológicas de aprovação ou reprovação que forneceriam o conteúdo da moralidade e ipso facto justificariam enunciados morais. Enunciados morais seriam, assim, reduzidos a enunciados descritivos sobre a natureza humana.

Dessa forma, para Korsgaard, o sentido em que o senso moral aprova a si mesmo, no modelo de Hume, é o de conferir normatividade, autoridade 
ou justificação a si próprio (em sua forma explanatória), isto é, aos seus mecanismos e princípios abstratos ou metafísicos, com o auxílio da crença (meta-ética) de que a natureza humana é a única fonte das distinções morais. É trivial como, segundo esta interpretação, o "anatomista moral” pode ajudar o "pintor moral". Em última instância, não há uma diferença entre o trabalho e a atividade de ambos. A teoria de Hume teria servido para mostrar que o trabalho do pintor das qualidades morais pode ser reduzido ao trabalho do anatomista da moral.

Mas, como veremos, temos razões para manter uma distinção conceitual entre as atividades do anatomista e do pintor, como o próprio Hume explicitamente diz.

\section{3 - Por que 0 argumento do regresso não se aplica a Hume}

As premissas (H6) e (H7) dizem que conferimos valor aos objetos através de nossos sentimentos naturais de aprovação e que tais objetos têm valor simplesmente porque são objetos de nossos sentimentos naturais de aprovação. O que elas querem dizer exatamente?

Uma das interpretações para as premissas em questão seria dizer que elas propõem, como um enunciado meta-ético, uma análise de 'bom'. Neste sentido, 'bom' significaria 'sentimentos naturais de aprovação'. Vimos que há, de fato, passagens em que Hume sugere algo próximo a esta proposição de caráter reducionista (naturalista). Ademais, a motivação básica do naturalista reducionista é descobrir verdades morais como as demais ciências empíricas o fazem. E o projeto de Hume, de caráter cientificista, poderia se coadunar, à primeira vista, com este tipo de interpretação ${ }^{27}$.

Se (H6) e (H7), em sua interpretação meta-ética, fornecem uma análise redutivista de enunciados valorativos em termos de enunciados descritivos sobre a natureza humana, então se segue trivialmente que (H6) e (H7) fornecem também o conteúdo daquilo que é bom. (H6) e (H7) seriam, assim, também enunciados éticos de primeira-ordem. Neste sentido, os resultados aos quais Hume teria chegado com sua teoria psicológica sobre a origem da moralidade forneceriam os critérios para julgarmos algo bom. De acordo com esta intepretação, algo é bom quando é objeto de certos sentimentos naturais de

\footnotetext{
${ }^{27}$ Embora Hume negue que sua teoria moral tenha mostrado que 0 objeto da moralidade é passível de investigação científica, como veremos adiante.
} 
aprovação. E, pelo mesmo raciocínio, tais sentimentos naturais de aprovação são julgados igualmente bons porque são simplesmente uma manifestação da natureza humana, que é a condição incondicional do valor de todos os objetos de nossas escolhas. O senso moral seria, assim, normativo.

No que se segue, tentaremos refutar tanto a interpretação meta-ética quanto a interpretação ética (de primeira-ordem) das premissas (H6) e (H7). Isto consistirá um primeiro passo para rejeitarmos a interpretação de Korsgaard do projeto Humeano e argumentarmos contra a validade do argumento do regresso que Korsgaard parece atribuir a Hume.

Cabe dizer que, do fato de que (H2) objetos ou têm valor independentemente de nossos sentimentos naturais de aprovação ou têm valor porque nossos sentimentos naturais de aprovação lhes conferem valor e de que $(\mathrm{H} 4)$ o realismo moral é falso, não é claro que a melhor explicação para a compreensão de 'valor' seja que os objetos de nossos sentimentos naturais de aprovação têm valor simplesmente porque são objetos de nossos sentimentos naturais de aprovação. Poderia ser o caso que os objetos de nossos sentimentos naturais de aprovação tivessem valor porque são a expressão de nossos sentimentos naturais de aprovação - em que 'porque' deve ser lido como uma cláusula explicativa. Neste sentido, como uma teoria explicativa de nossos juízos de valor, poderíamos dizer que valor é projetado através de nossos sentimentos naturais. Mas isto não significaria dizer absolutamente que tais sentimentos naturais devem fazer parte do conteúdo de nossos juízos morais. Eles seriam a condição de possibilidade explicativa para a formulação de tais juízos, mas não uma condição de possibilidade que cumpra um papel justificatório do uso de conceitos morais.

Assim, (H6) e (H7) poderiam receber uma leitura expressivista em termos meta-éticos, que em nada reduzem um enunciado valorativo a um enunciado descritivo da natureza humana ${ }^{28}$. Ainda assim, mesmo que rejeitemos a leitura meta-ética, poderia ser o caso que a leitura ética (de primeira-ordem) de (H6) e (H7) fosse verdadeira ${ }^{29}$. Não obstante, embora

\footnotetext{
${ }^{28}$ Sobre os detalhes de um projeto expressivista contemporâneo, na esteira de Hume, ver BLACKBURN, 1998, e GIBBARD, 1990. Para a distinção entre reportar e expressar um estado mental, ver GIBBARD, Idem, cap. 8. Basicamente, uma teoria expressivista em moral defende que juízos morais são expressões de estados mentais não-cognitivos e não-representacionais.

${ }^{29}$ Note que 0 condicional que vimos anteriormente era: se $(\mathrm{H} 6)$ e $(\mathrm{H} 7)$ são verdadeiras sob uma leitura metaética reducionista naturalista, então $(\mathrm{H} 6)$ e $(\mathrm{H} 7)$ são necessariamente verdadeiras sob uma leitura ética de primeira-ordem. Mas o fato de que $(\mathrm{H} 6)$ e $(\mathrm{H} 7)$ são falsas sob uma leitura meta-ética reducionista naturalista nada nos diz sobre sua verdade ou falsidade sob uma leitura ética de primeira-ordem.
} 
muitas das verdades éticas de primeira-ordem sejam difíceis de se estabelecer sem controvérsias, parece absolutamente falso que algo seja julgado bom porque é o objeto de nossos sentimentos naturais - em que 'porque' cumpriria um papel justificatório. Isto não parece ser uma razão justificatória sobre por que algo deve ser considerado bom ou não. Portanto, a leitura ética (de primeira-ordem) das premissas em questão parece ser ainda menos promissora do que a leitura meta-ética das mesmas.

Há passagens em que Hume parece sugerir justamente tal leitura expressivista. Ele diz, por exemplo, na segunda Investigação:

Quando [um homem] confere a alguém os epítetos de corrupto, odioso ou depravado, ele (...) expressa sentimentos, que espera que toda a sua audiência irá com ele compartilhar. Ele deve (...) adotar um ponto de vista comum a si e aos outros (...). (EPM, IX.i, p. 272) $)^{30}$.

É certo que 'expressar um ato da mente' é algo recorrente no texto de Hume $^{31}$. Mas, por outro lado, é igualmente certo que Hume não é rigoroso em seu uso desta terminologia e não parecia efetivamente ter clareza sobre uma distinção entre reportar e expressar um estado mental. Assim, apesar de podermos encontrar evidência textual que nos permita propor uma leitura expressivista do projeto de Hume, que por si só invalidaria parte do argumento de Korsgaard, deve-se reconhecer que esta não é uma leitura incontroversa. Para que uma defesa completa desta interpretação fosse fornecida, mostrando que ela se harmonizaria melhor com uma série de outros compromissos de Hume, precisaríamos dizer muito mais do que simplesmente apontar algumas passagens. Apesar disto, para os propósitos de nossa discussão aqui, será suficiente apontar passagens em que Hume nega que seu projeto seja reducionista, tal como Korsgaard parece interpretá-lo. Veremos mais adiante detalhes sobre este ponto, quando abordarmos uma discussão travada por Hume com Hutcheson e Butler. Mas, antes disto, vale notar que temos ainda outras razões para colocar em questão, na segunda parte do argumento de Korsgaard, também a premissa (H10).

\footnotetext{
30 Ver também THN (III.i.2, p. 471); THN (III.ii.2, p. 490); THN (III.iii.1, 582); EPM (IX.i).

${ }^{31}$ Ver passagens em THN (III.ii.2; III.ii.5; III.iii.1) e EPM (II.i; III.ii; V.ii; IX.i; Appendix I).
} 
A premissa (H10), tal como figura no argumento que vimos acima, parece carecer de uma defesa adicional. Descobrir que a natureza humana é a condição incondicional do valor de qualquer outra coisa - supondo a teoria meta-ética de Hume e sua explicação naturalista da origem dos juízos morais - não se segue que ela mesma deva ter valor e seja, portanto, normativa. Algo pode ser condição do valor de outro algo sem ser ele mesmo dotado de valor $^{32}$. Assim, a natureza humana poderia ser a condição de possibilidade de todas as minhas distinções morais, mas ainda assim não figurar em meus juízos morais como algo com relação a que eu devo reconhecer valor. É verdade que, segundo a teoria de Hume, nada teria valor no mundo sem as reações características da natureza humana. Mas isto não implica conferir valor intrínseco à própria natureza humana.

Diante destas considerações, e tendo questionado a atribuição do argumento do regresso a Hume - tal como Korsgaard parece formulá-lo podemos agora considerar mais claramente uma proposta alternativa de interpretação do projeto moral Humeano e explicar de outra maneira (que parece, como veremos, mais fiel ao texto de Hume) o processo reflexivo de aprovação do senso moral, mencionado no início de nossa discussão.

Primeiramente, devemos reconhecer o sentido trivial em que o senso moral pode aprovar a si mesmo. Neste sentido, o senso moral necessariamente aprova a si mesmo na medida em que ele só pode julgar a si mesmo por seus próprios padrões ${ }^{33}$. Se o senso moral aprova, através do mecanismo natural de simpatia, traços de caráter que são agradáveis e úteis aos seus possuidores e àqueles que estão a sua volta, então o senso moral necessariamente aprovará a si próprio na medida em que ele aprova tudo aquilo que tenha como resultado (ou que contribua para) a aprovação de traços de caráter que são agradáveis e úteis aos seus possuidores e àqueles que estão a sua volta. $\mathrm{O}$ senso moral aprova a si próprio porque necessariamente aprova os efeitos ou resultados de si mesmo. Neste sentido, o senso moral, ao refletir sobre seus próprios princípios, só pode aprovar a si mesmo no sentido de confirmá-lo ou reforçá-lo.

\footnotetext{
32 MOORE (1903, p. 144ss.) argumentou a favor desta possibilidade através de sua teoria das unidades orgânicas. No caso em questão, poderíamos dizer que, ainda que a natureza humana fosse condição de possibilidade de todo valor, aquilo que possui valor intrínseco poderia se limitar aos objetos de sentimentos. Assim, a natureza humana poderia ser entendida como possuindo valor instrumental.

${ }^{33}$ Hume parece sugerir isto em carta a Hutcheson. Ver abaixo.
} 
Mas poderia o senso moral aprovar a si mesmo além deste sentido trivial? À primeira vista, para Hume, não - ao menos se o que está em jogo é um sentido de aprovação que justifica o senso moral. Por outro lado, Hume parece inteiramente disposto a admitir que o senso moral pode aprovar a si mesmo, em um outro sentido de 'aprovação'. Neste segundo sentido, o que podemos extrair é uma espécie de confirmação (mas não justificação) da prática da moralidade, ao se refletir sobre os princípios que estão na base de nosso comportamento moral. Mas, para compreendermos melhor a resposta de Hume acerca deste ponto, será instrutivo analisar a questão à luz do que Hutcheson nos diz a respeito do tema (que tem, por sua vez, influência de Butler), haja vista que aquilo que Hume fala sobre o senso moral aprovar a si mesmo é uma referência direta à posição de Hutcheson sobre o tema.

Hutcheson também considerara que o caráter reflexivo da mente humana torna possível que coloquemos em questão e perguntemos pela validade de qualquer princípio operativo em nossa mente. Assim, da mesma forma e anteriormente a Hume, Hutcheson levantou a questão sobre que tipo de resposta o senso moral poderia dar ao refletir sobre si mesmo. Por um lado, Hutcheson defende que não seria adequado concluir que o senso moral julga a si mesmo bom, em um sentido literal ${ }^{34}$. Por outro lado, Hutcheson sugere que o entendimento poderia concluir que o senso moral deve ser seguido: que aquilo que o senso moral aprova deve ser um comando para nossas ações, que o senso moral tem autoridade para nós ${ }^{35}$. Este seria um requerimento cuja "validade" deveria ser reconhecida ao se refletir sobre o senso moral.

Se podemos, portanto, concluir que o senso moral tem autoridade para nós (que deve ser seguido), ao se refletir sobre ele e seus mecanismos

\footnotetext{
${ }^{34}$ HUTCHESON, 1749, Sec.1, p. 212: "Ninguém pode aplicar atributos morais à própria faculdade de perceber qualidades morais." Em seu A System of Moral Philosophy (1755), Hutcheson diz: "Nós não chamamos o próprio senso [moral] de virtuoso, mas possuir este senso em um alto grau naturalmente dá origem a um desejo por ter todas as afecções generosas. (...) Como a mente pode tornar quaisquer de seus próprios poderes objeto de sua contemplação reflexiva, este alto senso de excelência moral é aprovado como superior a todas as outras habilidades." (Idem, p. 67-8).

35 Cf. HUTCHESON, 1755, I, iv-vi, pp. 58-62. Hutcheson afirma existir uma diferença não apenas de grau, mas de tipo ou natureza, entre a reflexão de nível superior do senso moral e os sentimentos de nível inferior - em que o primeiro é capaz de corrigir os segundos e tem autoridade sobre estes. De acordo com Hutcheson, o senso moral é "naturalmente destinado a comandar todos os outros poderes." (Idem, p. 62). BUTLER (1983, p. 38) diz algo similar, ao discorrer sobre a diferença entre o princípio da consciência ou reflexão e as paixões: "(...) esta diferença, não sendo uma diferença em força ou grau, chamo de uma diferença de natureza e de tipo".
} 
subjacentes, vale notar que esta sugestão de Hutcheson aproxima-se de algo proposto por Korsgaard (acerca de Hume). A pergunta relevante é, mais uma vez: como verdades sobre a psicologia moral a que o anatomista chega (verdades meta-éticas) podem gerar também uma conclusão ética? Como vimos no caso da interpretação de Korsgaard, em um projeto reducionista naturalista isto é obviamente possível. Uma vez que as verdades do entendimento a que o anatomista chega fazem referência à natureza humana como sua condição última, se o entendimento concluir adicionalmente que o conteúdo da moralidade deve ser fornecido pelas manifestações desta mesma natureza humana, teremos uma conclusão com a convergência de um enunciado meta-ético e ético (normativo). Que o senso moral é normativo seria, assim, tanto um enunciado meta-ético redutivista quanto um enunciado ético sobre aquilo que é uma norma ou autoridade para nós. Neste sentido, a sugestão de Hutcheson parece convergir com a proposta de Korsgaard, no seguinte sentido: assim como Korsgaard, Hutcheson parece estar propondo que as manifestações de nossa natureza que estão na base de nosso comportamento moral devem ser normativas ou autoridade para nós temos razões para seguir tais manifestações de nossa natureza e, assim, corroborar a prática da moralidade como justificada $a^{36}$.

Mas isto parece ser justamente o que Hume quer evitar. Em carta, Hume acusa Hutcheson de que tal proposta seria um equívoco:

Você parece aqui adotar a opinião do Dr. Butler em seus sermões sobre a natureza humana de que nosso senso moral tem uma autoridade distinta de sua força e durabilidade, e isto porque sempre pensamos que ele deve prevalecer. Mas isto não é nada senão um instinto ou princípio, que aprova a si mesmo em reflexão, e que é algo comum a todos eles. ("To Hutcheson”, p. 148-9) ${ }^{37}$.

\footnotetext{
36 A bem da verdade, não é inteiramente claro que Hutcheson defendeu exatamente isto (Cf. HUTCHESON, 1749, p. 258). Ele parece estar convencido por Butler de que a faculdade do senso moral deve possuir um status superior ao de um "mero" sentimento; que ele precisa, tal como Butler, fazer uma distinção entre poder e autoridade de nossas faculdades mentais. (Cf. BUTLER, 1983, II.) Porém, não é claro que seja possível, na teoria de Hutcheson, conferir ao senso moral um status diferente do status de um mero sentimento sem, ao mesmo tempo, abandonar completamente o modelo sentimentalista. Ver IRWIN (2007, p. 543ss.) para uma discussão deste ponto.

${ }^{37}$ BURTON, 1875.
} 
Hume parece sugerir nesta passagem que o fato de se descobrir que os princípios abstratos ou metafísicos da moral revelam uma faculdade como o senso moral em nada implica que um 'deve' possa ser extraído da verdade desta teoria abstrata ou metafísica. $O$ fato de o senso moral explicar o funcionamento de juízos morais e de nosso comportamento moral nada nos diz, estritamente falando, sobre o que deve ser o caso. Assim, nem mesmo a descoberta de uma faculdade do senso moral - que, em Hume, nada mais é do que a nossa capacidade de ter sentimentos formados naturalmente como respostas a (descrições de) estados de coisas - nos autoriza a inferir que este mesmo senso moral deve ser seguido em nossas ações. Nossas distinções morais não são redutíveis a descrições sobre a natureza humana, incluindo o funcionamento de quaisquer faculdades.

Feitas essas distinções, estamos agora em condições de avaliar aquele argumento de Hume à luz de uma outra célebre passagem, no Tratado. Insistir nas teses de Hutcheson e Butler (à quais Korsgaard parece fazer eco) seria, em certo sentido, inferir um 'deve' de um 'é' - que, a menos que seja explicada a relação que conecte a premissa do argumento que contém um 'é' com o 'deve' que aparece na conclusão, estamos diante de uma falácia ${ }^{38}$. E Hume parece acreditar que nenhuma teoria é capaz de explicar uma tal relação que conecta um 'é' com um 'deve'. Ele diz claramente que a moralidade não é objeto de investigação científica ${ }^{39}$ e que as tarefas do anatomista e do pintor devem ser mantidas separadas ${ }^{40}$.

Hume parece, assim, defender que ambos, Hutcheson e Butler, estão errados. Mas, diante dessa sua resposta, surge o desafio: como Hume poderia garantir a autoridade e normatividade do discurso moral, a existência de requerimentos morais, se não é possível distinguir, a partir de nossa perspectiva de juízes morais, uma faculdade que tenha autoridade para nós? Mais especificamente, a dificuldade de Hume é a mesma que leva Hutcheson a propor uma distinção qualitativa entre o senso moral (de um ponto de vista reflexivo superior) e o mero sentir de nível inferior. Hutcheson é levado

38 Cf. THN (III.1.i, p. 469-70). Ver MACKIE (1980, p. 61-3) para uma discussão instrutiva deste argumento.

39 "Esse raciocínio prova não apenas que a moralidade não consiste em relações que são objetos da ciência; mas, se devidamente examinado, prova com igual certeza que ela não consiste em nenhuma questão de fato que possa ser descoberta pelo entendimento." (THN, III.1.i, p. 468)

${ }^{40}$ Ver abaixo citação de trecho de carta de Hume a Hutcheson. 
a concluir, na esteira de Butler, que o senso moral tem autoridade para nós e deve ser seguido independentemente de sua força frente a paixões contrárias.

Diante do que vimos, a resposta de Hume só pode ser que não há justificativa para a moralidade em termos não-morais. Segundo Hume, a justificativa da moralidade só pode ser dada pela própria perspectiva de juízes morais. E, assim, não é propriamente uma justificativa, mas apenas uma confirmação. Portanto, a partir da perspectiva de juízes morais, nem mesmo a faculdade do senso moral pode ser uma autoridade para nós, se com isso entendemos que devemos seguir os resultados ("upshots”) de uma faculdade específica. Esta faculdade pode explicar nossa capacidade de fazer distinções morais, mas ela mesma não é normativa para nós, pois esta faculdade não faz parte do conteúdo de juízos morais.

Estamos agora em condições de fazer uma distinção lógica entre a base (no caso de Hume, natural) de um requerimento moral e a ideia de justificação ou razões que são explicitadas na aplicação de um requerimento moral ${ }^{41}$. Um requerimento moral como "matar os pais é errado", por exemplo, não faz qualquer referência à sua base explicativa. Ele é um requerimento que simplesmente condena um ato de matar os pais ${ }^{42}$. Assim, podemos compreender o projeto de Hume, no que diz respeito ao aspecto justificatório do discurso moral, como sugerindo que não é possível nenhuma interpretação para o fato de o senso moral ser capaz de aprovar a si mesmo além da interpretação deste em seu sentido trivial. E, em última instância, Hume parece ter a seu favor a coerência de uma teoria psicológica que interpreta o comportamento humano como resultado de forças que variam em estabilidade e intensidade. Podemos, por vezes, agir

\footnotetext{
41 Cf. WIGGINS, 1995, p. 310. A posição aqui defendida parece se harmonizar, em larga medida, com 0 que Wiggins fala sobre o projeto moral de Hume.

42 Cf. THN (III.i.1, p. 466-7). Hume diz: "De todos os crimes que criaturas humanas são capazes de cometer o mais horrendo e inatural é a ingratidão, sobretudo quando é cometida contra os pais (...). Isto é reconhecido por toda a humanidade, tanto filósofos quanto pessoas comuns; a questão que surge apenas entre filósofos é se a culpabilidade ou deformidade moral dessa ação pode ser descoberta por raciocínio demonstrativo ou se é resultado de um sentido interno e por meio de algum sentimento, que a reflexão sobre tal ação naturalmente produz." Como fica claro nesta passagem, Hume não está discutindo se o conteúdo da injunção moral em questão deve fazer referência à razão ou ao sentimento. (Isto é relevante apenas em contextos filosóficos.) Afinal, o homem comum é capaz de reconhecer que parricídio é algo incorreto moralmente, ainda que não disponha de qualquer teoria filosófica sobre a origem deste juízo. Assim, Hume parece sugerir que, ao fornecermos uma razão ao homem comum sobre a incorreção do parricídio, não seria apropriado aqui uma referência às faculdades da razão ou sentimento.
} 
contrariamente aos nossos juízos morais, quando determinadas paixões contrárias se tornam mais fortes do que as paixões que estão na base do juízo moral. Mas o que explica "normatividade" e a nossa capacidade de condenar ações imorais é justamente a estabilidade (e, na maior parte das vezes, a força superior) que as paixões que estão na base de juízos morais têm naturalmente (isto é, na maior parte de seres humanos) em relação às demais. Assim, ao contrário de Hutcheson, Hume tem um modo de explicar normatividade sem precisar recorrer ao expediente de fazer uma distinção qualitativa entre forças que operam na mente humana (e cujo resultado são ações), ${ }^{43}$ conferindo normatividade a qualquer faculdade, incluindo a própria faculdade do senso moral - reduzindo, assim, enunciados valorativos a enunciados descritivos sobre a natureza humana.

Mas, se isto for verdade, pode, então, parecer que o anatomista não tem nada a oferecer ao pintor, contrariamente ao que Hume sugere. Esta é mesmo uma conclusão de nossa interpretação?

Como sabemos, Hutcheson havia reclamado em carta a Hume sobre a falta de entusiasmo deste em sua apresentação (no Tratado) dos mecanismos subjacentes à formação das virtudes ${ }^{44}$. Em resposta a Hutcheson, Hume reafirma sua distinção entre o anatomista e o pintor, que o seu trabalho é o de um anatomista e não o de um pintor, e que a sua omissão com relação à apresentação de uma defesa da virtude foi intencional. Hume diz em carta:

O que mais me tocou em seus comentários foi a sua observação de que falta um pouco de entusiasmo pela causa da virtude, pela qual, você pensa, todos os bons homens sentiriam satisfação, e não se entediariam em investigações abstratas. Devo reconhecer que isto não ocorreu por acaso, mas que é o resultado de um raciocínio, seja ele bom ou ruim. Há diferentes maneiras de examinar a mente assim como o

\footnotetext{
${ }^{43} \mathrm{Um}$ aspecto fundamental desta tese parece ser a distinção que Hume faz entre paixões violentas e calmas (THN, II.iii.3, p. 417-8). Como sabemos, esta distinção permite a Hume propor que aquilo que se parece (fenomenologicamente) com as operações da razão possa ser identificado com a atuação de paixões calmas. Deste modo, Hume pode introduzir a distinção entre a força fenomenológica e a força efetiva de uma paixão. Nem sempre as paixões mais fortes fenomenologicamente se traduzirão em ações. E nem sempre as paixões mais fortes efetivamente (de uma perspectiva global, isto é, considerando a psicologia do agente como um todo) se traduzirão em ações (localmente, isto é, em situações particulares). Ver THN (III.iii.1, p. 575), em que Hume vincula avaliação moral a "princípios duráveis da mente".

${ }^{44}$ Cf. BURTON, 1875, p. 111ss.
} 
corpo. Pode-se considerar ou como um anatomista ou como um pintor: ou descobrir os seus mais recônditos princípios e origens ou descrever a graça e a beleza de suas ações. Imagino que seja impossível unir estes dois pontos de vista. Quando se remove a pele e mostra todas a partes diminutas, surge algo trivial, mesmo nas mais nobres atitudes e mais vigorosas ações; e não se pode tornar o objeto gracioso ou cativante, exceto cobrindo novamente as partes com pele e matéria, e apresentando-as apenas em seu puro exterior. ("To Hutcheson") 45 .

Mas, apesar disto, Hume também deixa claro na continuação da carta que isto não significa dizer que a tarefa do anatomista não possa absolutamente auxiliar o pintor. Ele diz:

Um anatomista pode, porém, dar muitos bons conselhos a um pintor ou escultor. E, de forma semelhante, estou convencido de que o metafísico pode ser muito útil ao moralista, embora eu não possa facilmente conceber estes dois tipos unidos no mesmo trabalho. Qualquer sentimento moral [em tom] vigoroso, suspeito, teria o ar de uma declamação entre raciocínios abstratos, e seria considerado contrário ao bom gosto. E, embora eu tenha muito mais ambição de ser estimado como um aliado da virtude do que como um escritor de bom gosto, ainda assim devo sempre ter o último sob a minha mira. Do contrário devo perder as esperanças de ser útil à virtude ${ }^{46}$.

Apesar de Hume não especificar quais conselhos exatamente poderiam ser dados pelo anatomista ao pintor, podemos conjecturar vários desses com base no que vimos anteriormente. Coube a nós mostrar que aquela relação entre o anatomista e o pintor não é uma relação de justificação - o que Hume parece deixar claro mesmo nesta carta a Hutcheson, quando nega que o anatomista possa efetivamente se engajar em uma defesa da virtude. Mas, por outro lado, as descobertas do anatomista poderão ser de grande relevância para o pintor. Isto é o caso não apenas porque o pintor agora pode

${ }^{45}$ BURTON, 1875, p. 112-3.

${ }^{46} \mathrm{Ibid}$. 
ter conhecimento dos mecanismos subjacentes ao comportamento moral (o que, por si só, seria um instrumento poderoso para a "causa" da virtude). Mas também por haver uma razão geral por que o trabalho do anatomista - e os resultados específicos aos quais ele chega, segundo a teoria de Hume, que fazem referência, como vimos, à natureza humana - é de grande importância para o pintor. Aquilo que Hume descobre com sua anatomia da moral confirma a prática moral - ainda que não justifique o conteúdo da moralidade. Esta confirmação envolve uma "coexistência pacífica" entre as teorias do anatomista e do pintor. Apesar de não fazer referência especificamente ao conteúdo da moralidade, a anatomia moral de Hume pode ser entendida como uma confirmação geral do fenômeno da moralidade, da validade deste. Assim, ela pode ser entendida como tendo as seguintes implicações.

Ao mostrar que o fenômeno da moralidade tem origem na natureza humana (em particular, no mecanismo de simpatia), o anatomista moral Humeano pode agora fornecer ao pintor moral os intrumentos para um argumento contrário a uma explicação "ficcionalista" da moralidade (tal como defendida por autores como Mandeville), segundo a qual o discurso e o comportamento moral são resultado de um processo de manipulação (que, em última instância, promove o desenvolvimento de determinadas aptidões por reconhecimento público de ações), que tem o objetivo de preservar a ordem social; mas que, de um ponto de vista teórico, não passa de um discurso vazio, que satisfaz fins não-morais (como o da preservação de uma determinada classe dominante). Se o anatomista é capaz de mostrar que isto não é suficiente para sustentar o comportamento moral em geral, este resultado pode figurar como um forte argumento contra tal concepção "ficcionalista" da moralidade. A história naturalista de Hume supostamente fornece o material para preencher este hiato em teorias ficcionalistas como a de Mandeville ${ }^{47}$.

O anatomista pode agora também oferecer ao pintor os meios para rejeitar raciocínios metafísicos abstrusos, típicos de autores realistas e intuicionistas (como Samuel Clarke), que pleiteavam a existência de genuínas

\footnotetext{
${ }^{47}$ Em THN (III.iii.1, p. 578-9) isto é sugerido. Ver também THN (III.i.1, p. 455-6), quando Hume diz: "O que nos afeta, podemos concluir, nunca pode ser uma quimera." MANDEVILLE, 1997, apresenta uma defesa da posição referida aqui como ficcionalista. Para uma discussão detalhada do tópico e do sentido em que o projeto moral de Hume se distancia desta, ver LOVEJOY, 1961.
} 
realidades morais cujas verdades poderiam ser apreendidas por atos de intuição racional ou intelectual ${ }^{48}$. Ao mostrar que o fenômeno da moralidade pode ser perfeitamente bem explicado através de mecanismos internos à natureza humana, o anatomista fornece ao pintor um intrumento para que um argumento ao modo de "uma navalha de Occham" possa ser empregado contra teorias que defendem realidades (e relações entre propriedades) obscuras ou sui generis, e metafisicamente inflacionadas. Se o fenômeno da moralidade pode ser perfeitamente bem explicado por uma teoria metafisicamente mais econômica, como a de Hume, resta aos defensores de uma explicação metafísica mais inflacionada apresentarem razões para que sua explicação seja preferida.

Ainda na esteira deste ataque a certas formas de realismo, o anatomista moral Humeano também dispõe de recursos para a formulação de um argumento que explica a praticidade do discurso e pensamento morais ${ }^{49}$. Autores cognitivistas e realistas (intuicionistas sendo um destes) têm a dificuldade, inerente a sua teoria, de explicar tal caráter prático da moralidade, uma vez que entendem o pensamento e o discurso moral como sendo representacional e descritivo. Diante disto, a questão, portanto, é saber como a descoberta de uma tal realidade (independente das motivações humanas) pode levar um agente a agir (e fornecer uma razão para tal). Uma vez que, na anatomia moral de Hume, a explicação da praticidade do fenômeno moral se dá trivialmente, em função da relação lógica ou conceitual que há entre julgar algo moralmente e estar motivado a agir (pois aquilo que está na base de um juízo moral são entidades práticas e motivacionais por excelência, tais como paixões, sentimentos e desejos), a concepção meta-ética Humeana não enfrenta tal problema.

Por fim, o anatomista Humeano pode fornecer ao pintor uma teoria sobre a origem do discurso e do comportamento moral que pode figurar em um argumento contrário a uma concepção da moralidade como um constructo artificial e mero instrumento para a satisfação de anseios individuais egoístas - tal como autores como Hobbes defenderam. Como vimos, Hume está disposto a admitir que certos indivíduos podem ser

\footnotetext{
${ }^{48}$ Ver CLARKE, 1728.

${ }^{49}$ Devemos aqui nos lembrar que Hume enquadra a moralidade na dimensão prática de nossas vidas e parece tomar isto como uma característica própria do conceito de moralidade, que deve ser acomodada por qualquer teoria moral. Ver THN (III.i.1, p. 457).
} 
levados a agir moralmente apenas por motivações egoístas. Mas, por outro lado, um dos pontos centrais de Hume é mostrar como o mecanismo de simpatia pode produzir afetos em nós cujos objetos vão além de nós mesmos - isto é, afetos que são direcionados aos outros. Com isto Hume supôs mostrar que existe efetivamente tal coisa como motivação altruísta e a atitude de tomar o bem público como fim. Se isto é um resultado correto sobre a natureza das ações humanas, ainda que algumas virtudes (como a justiça) sejam originalmente artificiais, a sua prática pode torná-las naturais de tal forma que ao aprovarmos algo, podemos estar efetivamente aprovando a coisa que é objeto da aprovação sem precisarmos de uma explicação que faça referência a nós mesmos, individualmente, e a nossos anseios pessoais ${ }^{50}$.

Portanto, diante dos resultados alcançados com a anatomia moral, Hume teria fornecido material suficiente ao pintor moral para que este não precisasse ludibriar, subornar ou esconder algo a sua audiência sobre a natureza do comportamento moral, para convencê-la da "validade" do discurso e do agir moral ${ }^{51}$. Ao contar uma história sobre a origem destes, seguindo as descobertas do anatomista, confirmamos e reforçamos a prática moral, pois naquelas, como diz Hume, "de todos os lados, não se apresenta nada que não seja louvável e bom.” (THN, III.iii.6, p. 619) ${ }^{52}$. A anatomia moral Humeana não frustra as nossas próprias expectativas morais.

\section{4 - Conclusão}

Neste artigo discutimos a proposta interpretativa de Korsgaard do projeto moral de Hume e procuramos mostrar que temos razões para rejeitála. Em nossa reconstrução da interpretação de Korsgaard, vimos que uma forma análoga do argumento do regresso não parece se aplicar a Hume. Ao contrário da sugestão de Korsgaard, defendemos que a teoria abstrata ou metafísica Humeana dos princípios da moral não é uma teoria justificatória do conteúdo da moralidade, mas tão-somente uma teoria explicativa de nossos juízos e comportamento morais.

\footnotetext{
50 Cf. discussão em THN (III.iii.1) e EPM (Appendix II).

51 Ver nota 5 acima.

52 Outros aspectos da anatomia moral de Hume (não explorados aqui, mas) mencionados por outros autores são: o papel da educação moral, à luz do trabalho do anatomista; a relação entre um projeto meta-ético Humeano e uma ética (normativa) teleológica. Ver, respectivamente: BAIER, 1991, p. 185ss.; BLACKBURN, 1993.
} 
Ao mesmo tempo indicamos como Hume pode compatibilizar uma metafísica naturalista da moral com uma visão não-redutivista da natureza da moralidade e do dicurso moral. $\mathrm{Na}$ esteira desta discussão, vimos como Hume pode explicar a existência de requerimentos morais através de uma teoria psicológica que reconhece apenas as categorias de força e durabilidade na base e origem psicológica de nossas ações, e que, em última instância, cumpre apenas um papel de confirmação de nossas práticas morais.

Se a virtude da interpretação de Korsgaard é encontrar espaço para normatividade e requerimentos morais no projeto moral de Hume, a sua dificuldade está no fato de ela conseguir mostrar isto apenas de uma forma que não é capaz de evitar conclusões claramente anti-Humeanas.

\section{Referências bibliográficas}

BAIER, Annette. A Progress of Sentiments. Reflections on Hume's Treatise. Cambridge, Mass.: Harvard University Press, 1991.

BLACKBURN, Simon. "Errors and the Phenomenology of Value". In: Essays in Quasi-Realism. Oxford: Oxford University Press, 1993.

- Ruling Passions: A Theory of Practical Reasoning. Oxford:

Oxford University Press, 1998.

BURTON, John Hill (org.). Life and Correspondence of David Hume. Edinburgh: William Tait, 1875.

BUTLER, Joseph. Five Sermons Preached at the Rolls Chapel and a Dissertation upon the Nature of Virtue. S. Darwall (ed.), Indianapolis: Hackett, 1983. [1726; 1736].

CLARKE, Samuel. A Discourse Concerning the Unalterable Obligations of Natural Religion, and the Truth and Certainty of Christian Revelation. London: W. Botham, for J. and J. Knapton, 1728.

GIBBARD, Allan. Wise Choices, Apt Feelings: A Theory of Normative Judgment. Oxford: Oxford University Press, 1990.

HUME, David. A Treatise of Human Nature. L. A. Selby-Bigge (ed.), 2nd edition revised by P. H. Nidditch. Oxford: Clarendon Press, 1978. [17391740].

- Enquiry concerning Human Understanding, L. A. Selby-Bigge (ed.), 3rd edition revised by P. H. Nidditch. Oxford: Clarendon Press, 1975. [1748]. 
. Enquiry concerning the Principles of Morals, L. A. Selby-Bigge (ed.), 3rd edition revised by P. H. Nidditch. Oxford: Clarendon Press, 1975. [1751].

. "The Sceptic". In: Essays, Moral, Political, and Literary. Revised edition edited by Eugene F. Miller based on the 1777 edition originally published as volume 1 of Essays and Treatises on several subjects. Indianapolis: Liberty Fund, 1987.

HUTCHESON, Francis. An Inquiry into the Original of our Ideas of Beauty and Virtue. London: 1729.

. Illustrations upon the Moral Sense. Glasgow: Robert \& Andrew Foulis, 1749.

. A System of Moral Philosophy. Glasgow: Robert \& Andrew Foulis, 1755.

IRWIN, Terence. The Development of Ethics. Vol. II. Oxford: Oxford University Press, 2007.

KEMP-SMITH, Norman. The Philosophy of David Hume. London: Macmillan, 1941.

KORSGAARD, Christine. The Sources of Normativity. Cambridge: Cambridge University Press, 1996a.

. "Kant's Formula of Humanity". In: Creating the Kingdom of Ends. Cambridge: Cambridge University Press, $1996 \mathrm{~b}$.

- "Two Distinctions in Goodness". In: Creating the Kingdom of Ends. Cambridge: Cambridge University Press, 1996c.

- "Aristotle and Kant on the Source of Value". In: Creating the Kingdom of Ends. Cambridge: Cambridge University Press, 1996d.

LOVEJOY, Arthur O. Reflections on Human Nature. Baltimore: Johns Hopkins Press, 1961.

MACKIE, John L. Hume's Moral Theory. London: Routledge, 1980.

MANDEVILLE, Bernard. The Fable of the Bees and other Writings. E. J. Hundert (ed.). Indianapolis: Hackett, 1997. [1714] .

MOORE, George E. Principia Ethica. Thomas Baldwin (ed.). Cambridge: Cambridge University Press, 1993. [1903].

RIDGE, Michael. "Why Must we Treat Humanity with Respect? Evaluating the Regress Argument”. In: European Journal of Analytic Philosophy, 2005: 57-74. 
SHAFTESBURY, Anthony Ashley Cooper. "An Inquiry Concerning Virtue or Merit”. In: Characteristicks of Men, Manners, Opinions, Times. Vol. II, Tr. IV, 1727.

SINNOTT-ARMSTRONG, Walter. "Moral Skepticism and Justification”. In: Sinnott-Armstrong, W. \& Timmons, M. (eds.) Moral Knowledge?: New Readings in Moral Epistemology. New York: Oxford University Press, 1996: 3-48.

TIMMERMANN, Jens. "Value without Regress: Kant's Formula of Humanity Revisited”. In: European Journal of Philosophy, 14(1), 2006: 69-93.

WIGGINS, David. "Categorical Requirements: Kant and Hume on the Idea of Duty”. In: Hursthouse, R., Lawrence, G. \& Quinn, W. (eds.). Virtue and Reasons: Philippa Foot and Moral Theory. Oxford: Clarendon Press, 1995.

Email: ribeiro.lm@gmail.com

Recebido: fevereiro de 2012 Aprovado: abril de 2012 